\title{
BCL2 expression in CD105 positive neoangiogenic cells and tumor progression in angioimmunoblastic T-cell lymphoma
}

Philippe Ratajczak ${ }^{1,2}$, Christophe Leboeuf ${ }^{1,2}$, Li Wang ${ }^{1,2,3}$, Josette Brière ${ }^{1,2,4}$, Irmine Loisel-Ferreira ${ }^{1,2}$, Catherine Thiéblemont ${ }^{1,2,5}$, Wei-Li Zhao ${ }^{1,3}$ and Anne Janin ${ }^{1,2,4}$

${ }^{1}$ Inserm, U728, Paris, France; ${ }^{2}$ Univ Paris Diderot, Sorbonne Paris Cité, Laboratoire de Pathologie, UMRS 728, Paris, France; ${ }^{3}$ State Key Laboratory of Medical Genomics, Shanghai Institute of Hematology, Pôle de Recherches Franco-Chinois en Science du Vivant et Génomique, Shanghai Rui Jin Hospital, Shanghai Jiao Tong University School of Medicine, Shanghai, China; ${ }^{4}$ AP-HP-Hôpital Saint-Louis, Laboratoire de Pathologie, Paris, France and ${ }^{5}$ AP-HP-Hôpital Saint-Louis, Service d'Hémato-Oncologie, Paris, France

The angiogenic microenvironment has been known to be a component of angioimmunoblastic T-cell lymphoma since its initial characterization. We have shown that angioimmunoblastic T-cell lymphoma endothelial cells produce vascular endothelial growth factor-A (VEGFA), and participate in lymphoma progression. In squamous cell carcinoma, endothelial BCL2 expression induces a crosstalk with tumor cells through VEGFA, a major mediator of tumoral angiogenesis. In the present study, we analyzed BCL2 and VEGFA in 30 angioimmunoblastic T-cell lymphomas, using triple immunofluorescence to identify protein coexpression in wellcharacterized lymphoma cells and microenvironment neoangiogenic endothelial cells. Using quantitative real-time PCR, we assessed mRNA expression levels in laser-microdissected endothelial and lymphoma cells. In lymphoma cells, as in endothelial cells, BCL2 and VEGFA proteins were coexpressed. BCL2 was expressed only in neoangiogenic $\mathrm{CD} 34^{+} \mathrm{CD} 105^{+}$endothelial cells. In laser-microdissected cells, mRNA studies showed a significant relationship between BCL2 and VEGFA levels in CD34 ${ }^{+}$endothelial cells, but not in $\mathrm{CD}^{+}{ }^{+} \mathrm{CD} 10^{+}$lymphoma cells, or in $\mathrm{CD}^{+} 4^{+}$endothelial cells from lymph node hyperplasia. Further study showed that, in AITL, BCL2 mRNA levels in $\mathrm{CD}_{4}{ }^{+} \mathrm{CD}_{105}{ }^{+}$neoangiogenic endothelial cells also correlated with microvessel density, International Prognostic Index, Ann Arbor stage, bone marrow involvement and elevated LDH. BCL2 expression by $\mathrm{CD}_{105}{ }^{+}$neoangiogenic endothelial cells is related to tumor progression in angioimmunoblastic T-cell lymphoma.

Modern Pathology (2012) 25, 805-814; doi:10.1038/modpathol.2012.1; published online 10 February 2012

Keywords: angioimmunoblastic T-cell lyphoma; BCL2; CD105; endothelial cell; neoangiogenesis; VEGF

The angiogenic microenvironment has been known to be a component of angioimmunoblastic T-cell lymphoma since its initial characterization. ${ }^{1,2} \mathrm{We}$ have shown that endothelial cells in invasive areas of angioimmunoblastic T-cell lymphoma produce vascular endothelial growth factor-A (VEGFA), and participate in tumor progression by an autocrine effect involving the VEGF-R1 receptor. ${ }^{3}$ The

Correspondence: Professor A Janin, MD, PhD, U728, Laboratoire de Pathologie, Hôpital Saint-Louis, 1 Avenue Vellefaux, 75010 Paris, France.

E-mail: anne.janin728@gmail.com

Received 5 August 2011; revised 23 October 2011; accepted 23

October 2011; published online 10 February 2012 importance of highlighting the association of VEGFA with angioimmunoblastic T-cell lymphoma is its potential role for antiangiogenic therapy in this disease. $^{4-7}$

In oral squamous cell carcinoma, a crosstalk between endothelial and tumor cells mediated by BCL2 through VEGF and its receptors has been recently identified. ${ }^{8}$ In a murine model of xenografted human squamous cell carcinoma cell lines, BCL2-transfected endothelial cells increase: (i) tumor growth, ${ }^{8}$ (ii) tumor invasion, as measured on matrigel, and (iii) lung metastases number. ${ }^{9}$ In this model, BCL2 expression by endothelial cells of tumor areas induces VEGFA overexpression by the same endothelial cells. 
Hypoxia can also induce BCL2 expression in human aortic endothelial cells through p38 MAPK pathway. ${ }^{10}$ In vitro, BCL2 expression is able to protect human dermal endothelial cells from apoptosis, independently of cytochrome c release, by increasing survivin expression, and inhibiting p53 and p38 MAPK accumulation. ${ }^{11}$ Moreover, blocking BCL2 activity alters in vitro endothelial cell growth and tubular morphogenesis. ${ }^{12}$

Neoangiogenic endothelial cells can be characterized in solid tumor by expression of CD105, a TGF $\beta$ R type III auxiliary receptor. ${ }^{13}$ In meningiomas, glioblastomas, and squamous cell carcinoma, CD105 expression on endothelial cells is related to neoangiogenesis and to tumor progression. ${ }^{14-16}$ CD105 is also expressed by endothelial cells in the primary central nervous system lymphomas and correlates with survival. ${ }^{17}$

Here, we studied BCL2 and VEGFA expression in neoangiogenic endothelial cells and lymphoma cells in angioimmunoblastic T-cell lymphoma.

\section{Materials and methods}

\section{Patient Selection}

In all, 30 patients with angioimmunoblastic T-cell lymphoma (14M/16F, 33-84 years, median 60 years) were included in this study. Histological diagnoses were established according to the WHO classification. ${ }^{18}$ Induction chemotherapy was six cycles of CHOP and CHOP-like regimen followed by consolidation and maintenance chemotherapies as previously reported. ${ }^{19}$ Eight age- and sex-matched patients with lymph node hyperplasia were referred as controls. Approval was obtained from the Institut Universitaire d'Hématologie-Hôpital Saint-Louis institutional review board. All patients gave their informed consent.

\section{Tissue Specimen}

Lymph nodes, surgically removed for diagnostic purpose, were immediately cut: one part was fixed in formaldehyde and further processed for paraffin embedding, another part was snap-frozen. Bone marrow biopsies were performed in all 30 patients with angioimmunoblastic T-cell lymphoma, and skin biopsies in 11 patients with angioimmunoblastic T-cell lymphoma with skin rash.

\section{Microvessel Density}

The microvessel density was evaluated by endothelial cell immunostaining with CD34 antibody (clone QBEnd10, Beckman Coulter). Angiogenesis assessment was based on the method of Weidner et $a l^{20}$ and international consensus criteria for angiogenesis quantification. ${ }^{21,22}$ Microvessels were counted at $\times 400$ magnification on five different fields. The microvessel density of each specimen was calculated as the mean value of the different counts. Five normal lymph nodes were used as controls for microvessel density measurement.

\section{MKI67 Labeling Index Assessment}

MKI67 labeling index was assessed using mouse monoclonal MIB1 antibody (Dako, France) with an indirect immunoperoxidase method. MKI67 labeling index was calculated as the percentage of positive nuclei for MKI67 staining at $\times 400$ magnification on five different fields. In the case of heterogeneous staining, areas containing the largest and smallest number of positive cells were selected and the percentages were averaged to give the MKI67 labeling index.

\section{Triple Immunofluorescent Labelings}

Triple immunofluorescent labelings were performed to assess coexpression of BCL2/CD34/CD3 and BCL2/CD34/VEGFA. Since three of the four primary antibodies were mouse antibodies of the IgG1 isotype, they each required binding to different fluorophores using Apex-Alexa or Zenon kits (Invitrogen, France). CD34 antibody (clone QBEnd10, Beckman Coulter) was thus bound with Apex to Alexa 594, BCL2 antibody (clone 124, Dako) with Apex to Alexa 488, and VEGFA antibody (clone 1316, Abcam) with Zenon to Alexa 350. CD3 antibody, a rabbit polyclonal antibody (Biocare Medical), was bound with Apex to Alexa 488.

For further study of neoangiogenic $\mathrm{CD}_{105}{ }^{+}$ endothelial cells, triple BCL2/CD34/CD105 immunofluorescent labeling was performed, with CD34 antibody bound with Apex to Alexa 594, BCL2 antibody bound with Apex to Alexa 488, and CD105 mouse antibody (clone SN6h, Abcam) bound with Zenon to Alexa 350.

Tissue sections were analyzed by two different pathologists (AJ and $\mathrm{PR}$ ) on a motorized $Z$-axis Olympus (Tokyo, Japan) BX 61 microscope. Microscopic pictures were captured through a UPlan Fl/ $40 \times / 0.75$ objective with a digital camera ColorView III using Olympus-SIS Cell F software.

\section{Laser-Microdissection Combined to Molecular Analyses}

Laser-microdissection was performed on $7 \mu$ m-thick lymph node frozen sections after immunofluorescent staining; after acetone post-fixation $5 \mathrm{~min}$ at $4^{\circ} \mathrm{C}$, sections were incubated for $5 \mathrm{~min}$ with antibodies bound to fluorophores, using Zenon kits (Invitrogen, France). CD34 antibody (clone QBEnd10, Beckman Coulter), CD105 (clone SN6h, 
Abcam), CD3 (rabbit polyclonal, Biocare Medical) were bound to Alexa 488, and CD10 (clone 56C6, Novocastra) to Alexa 594.

In the 30 angioimmunoblastic T-cell lymphoma lymph node sections, laser-microdissection was performed: (i) for lymphoma cells, identified as $\mathrm{CD}^{+} \mathrm{CD}^{+} 0^{+}$medium-sized cells, ${ }^{23-25}$ (ii) for CD $34^{+}$ endothelial cells, and (iii) for $\mathrm{CD} 105^{+}$neoangiogenic endothelial cells, on different successive frozen sections.

A quantitative assessment was achieved by PALM Robo software (Zeiss-Palm, Germany). For each patient, $\sim 500 \mathrm{CD} 3{ }^{+} \mathrm{CD} 10^{+}$lymphoma cells corresponding to an average surface of $170000 \mu \mathrm{m}^{2}, 500$ $\mathrm{CD}^{+} 4^{+}$endothelial cells, and $500 \mathrm{CD} 105^{+}$neoangiogenic endothelial cells, corresponding to an average surface of $100000 \mu \mathrm{m}^{2}$, were microdissected and catapulted into tubes for RNA extraction.

In the eight lymph node hyperplasia frozen sections, laser-microdissection was performed to select: (i) for $\mathrm{CD}^{+}$small-lymphocyte cells in interfollicular areas and (ii) $\mathrm{CD}^{+} 4^{+}$endothelial cells, on different successive frozen sections.

Total RNA was extracted using Trizol reagent (Invitrogen, Carlsbad, CA, USA). First-strand cDNA was synthesized using Superscript II reverse transcriptase (Invitrogen) according to the manufacturer's instructions.

Ascertainment of the specificity of laser-microdissected cells was systematically performed using quantitative real-time PCR:

- CD34 ${ }^{+}$-microdissected cells from angioimmunoblastic T-cell lymphoma and lymph node hyperplasia were considered as endothelial cells since they expressed CD31 mRNA but not CD3e or CD10 mRNA.

- $\mathrm{CD}^{+} \mathrm{CD} 10^{+}$-microdissected cells from angioimmunoblastic T-cell lymphoma were considered as lymphoma cells since they expressed CD10 mRNA but not CD31 mRNA.

- $\mathrm{CD} 3^{+}$-microdissected cells from lymph node hyperplasia were considered as lymphocytes since they expressed CD3e but not CD31 mRNA.

Quantitative real-time PCR was performed on an ABI PRISM 7700 system using the Pre-Developed TaqMan Assay Reagent specific for human CD3 $\varepsilon$ (Hs01062241_m1), CD10 (Hs00153510_m1), CD31 (Hs00169777_m1), BCL2 (Hs00608023_m1), and VEGFA (Hs00900055_m1), and for human transcription factor IID/TATA-binding protein (TBP) gene expression quantification (PE Applied Biosystems, UK). The TBP gene was used as an internal control. Results were quantified using the comparative cycle threshold (Ct) method. Jurkat and MCF7 cells, which respectively express the BCL2 and VEGFA genes, were used as calibrators. ${ }^{3,26}$ CD3 $\varepsilon$, CD10 and CD31 mRNA expressions were first assessed, to check the laser-microdissection selection of cell populations.

\section{Statistical Analyses}

Patient characteristics were compared using $\chi^{2}$ and Fisher's exact tests for categorical variables, and Wilcoxon's test for continuous variables. Event-free survival was calculated from the date of diagnosis to the date of progression, relapse, or death. Overall survival was measured from the date of diagnosis to either death from any cause or the stopping date of 1 January 2008. Survival rates were estimated using the Kaplan-Meier method and compared by logrank test. Multivariate survival analysis was performed using a Cox regression model. Difference were considered significant when the two-sided $P$-value was $<0.05$. Difference were considered significant when the two-sided $P$-value was $<0.05$. All statistical analyses were performed using SAS 8.2 software (SAS Institute, Cary, NC, USA).

\section{Results}

\section{BCL2 Expression in AITL Endothelial Cells}

Using two different methods, multiple fluorescent immunostainings for BCL2 and CD34 (Figure 1), and laser-microdissection combined with molecular quantitative analyses (Figure 2; Table 1), we identified BCL2 protein in angioimmunoblastic T-cell lymphoma CD34 ${ }^{+}$endothelial cells (Figure 1) and showed a significantly higher expression of BCL2 mRNA in angioimmunoblastic T-cell lymphoma endothelial cells $(3.27 \pm 0.31)$ than in lymph node hyperplasia endothelial cells $(1.34 \pm 0.17)$ $(P=0.009)$. With the same methods used for lasermicrodissected $\mathrm{CD}^{+}{ }^{+} \mathrm{CD} 10^{+}$lymphoma cells, we showed a significantly higher expression of BCL2 mRNA in angioimmunoblastic T-cell lymphoma cells $(28.34 \pm 2.34)$ than in lymph node hyperplasia $\mathrm{CD}^{+}$lymphocytes $(17.47 \pm 1.07)(P=0.007)$.

In the 30 patients with angioimmunoblastic T-cell lymphoma, $27.4 \pm 5.3 \%$ of CD $34^{+}$endothelial cells expressed CD105 neoangiogenic marker but were not detected in the eight patients with lymph node hyperplasia (Figure 3).

With BCL2/CD34/CD105 triple immunofluorescent labeling (Figures 4 and 5), in the 30 patients with angioimmunoblastic T-cell lymphoma, BCL2 was only identified in $\mathrm{CD}_{34}{ }^{+} \mathrm{CD} 105^{+}$neoangiogenic endothelial cells (Figures 4 and 5). In these patients, $24.7 \pm 4.1 \%$ of $\mathrm{CD}_{34}{ }^{+}$endothelial cells were double positives for CD105 and BCL2 (Figure 3).

To get further insight into BCL2 expression by angioimmunoblastic T-cell lymphoma endothelial cells, CD105 ${ }^{+}$neoangiogenic endothelial cells were laser-microdissected and quantitative molecular analyses performed (Figure 6; Table 1). There was a significantly higher expression of BCL2 mRNA in angioimmunoblastic T-cell lymphoma neoangiogenic $\mathrm{CD} 105^{+}$endothelial cells $(8.62 \pm 2.87)$ than in laser-microdissected $\mathrm{CD}^{+} 4^{+}$endothelial cells $(3.27 \pm 0.31)(P=0.027)$. 


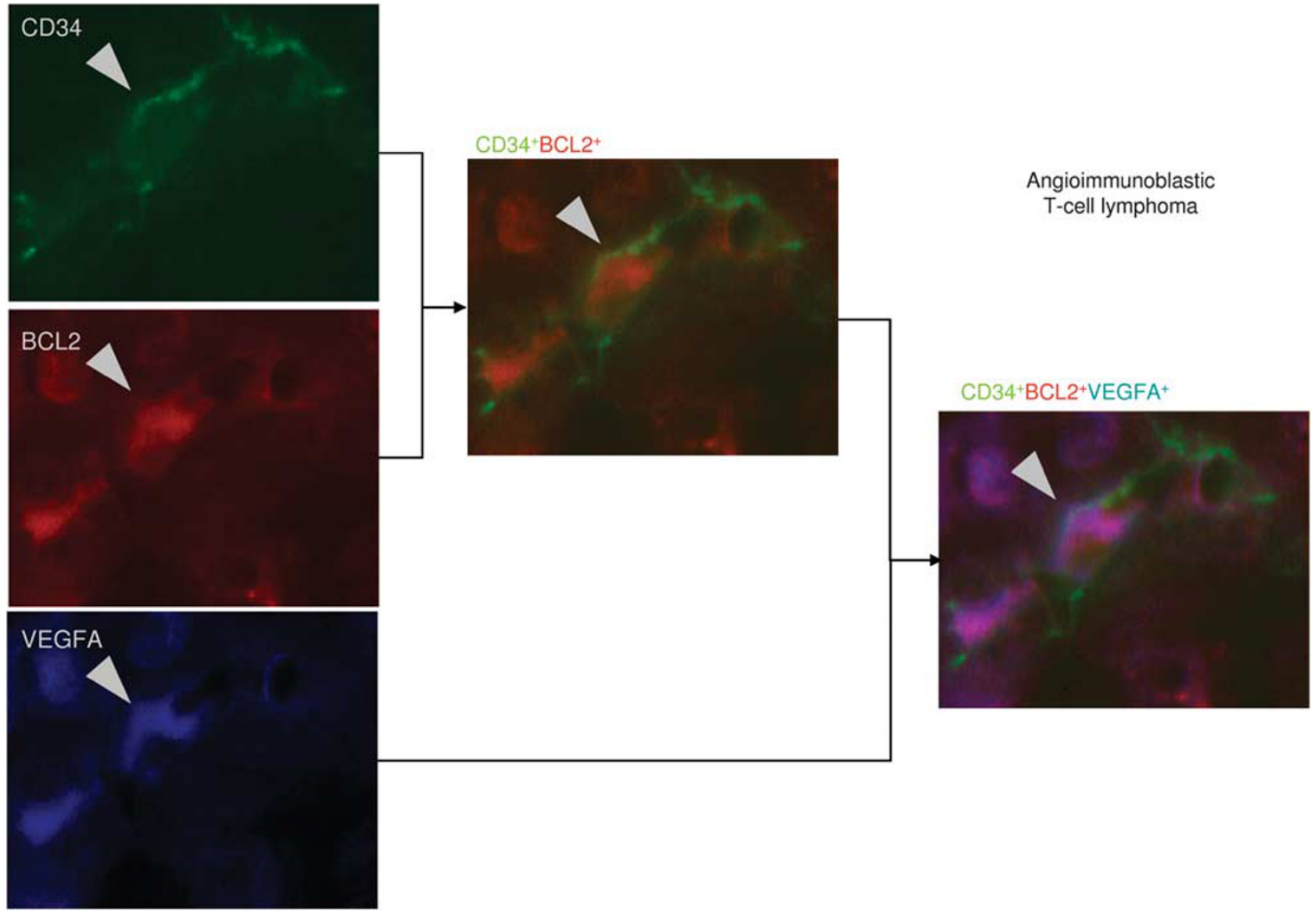

Figure 1 BCL2 and VEGF expression in endothelial cells of angioimmunoblastic T-cell lymphoma. Coexpression of BCL2, VEGFA on angioimmunoblastic T-cell lymphoma CD $34^{+}$endothelial cells (triple immunofluorescent staining: BCL2 in red, VEGFA in blue and CD34 in green).

\section{BCL2 and VEGFA Coexpression in Angioimmunoblastic T-Cell Lymphoma Endothelial Cells}

Using BCL2/VEGFA/CD34 triple immunofluorescent labeling, we found a coexpression of BCL2 and VEGFA proteins in endothelial cells of angioimmunoblastic T-cell lymphoma (Figure 1), but not of lymph node hyperplasia endothelial cells.

Further qRT-PCR performed on laser-microdissected cells showed a significant difference of VEGFA mRNA expression (i) between $\mathrm{CD}^{+} 4^{+}$ endothelial cells of angioimmunoblastic T-cell lymphoma and of lymph node hyperplasia $(7.54 \pm 2.74$ VS $2.99 \pm 0.79, P=0.023$ ), and (ii) between CD3 ${ }^{+}$ $\mathrm{CD}^{+}{ }^{+}$angioimmunoblastic T-cell lymphoma cells and $\mathrm{CD}^{+}$lymph node hyperplasia lymphocytes (4.00 \pm 1.67 vs $0.51 \pm 0.06, P=0.012)$ (Table 1$)$.

The coexpression of BCL2 and VEGFA in endothelial cells of angioimmunoblastic T-cell lymphoma was also confirmed qRT-PCR of laser-microdissected cells. BCL2 and VEGFA mRNA levels were significantly related in endothelial cells of angioimmunoblastic T-cell lymphoma $\left(R^{2}=0.745, P<0.0001\right)$, but not of lymph node hyperplasia $\left(R^{2}=0.091, \quad P=0.2572\right) . \quad$ Moreover,
BCL2 and VEGFA mRNA levels are not correlated in $\mathrm{CD}^{+} \mathrm{CD}^{+} 0^{+}$angioimmunoblastic T-cell lymphoma cells $\left(R^{2}=0.072, P=0.1602\right)$ (Figure 2c and $\mathrm{d}$ ).

\section{AITL Endothelial BCL2 Expression and Tumor Progression}

In the 30 angioimmunoblastic T-cell lymphoma cases (Table 1; Figure 7), endothelial BCL2 mRNA expression was not linked with proliferation index, but it was significantly related with (i) microvessel density, (ii) International Prognostic Index, ${ }^{27}$ (iii) signs of tumor progression and extension (Bone marrow involvement, Ann Arbor Stage, elevated lactate dehydrogenase level). This contrasts with the absence of any clinical correlation with lymphoma cell BCL2 mRNA expression.

Further statistical analyses showed that BCL2 levels for $\mathrm{CD}_{34}{ }^{+}$and $\mathrm{CD} 105^{+}$laser-microdissected angioimmunoblastic T-cell lymphoma endothelial cells correlated with the same clinical data. However, the statistical significance was higher for $\mathrm{CD}_{105}{ }^{+}$neoangiogenic endothelial cells than for $\mathrm{CD}^{+}{ }^{+}$endothelial cells regarding (i) microvessel density $\quad\left(R^{2}=0.6412, \quad P<0.0001\right.$ vs $R^{2}=0.5444$, 
a
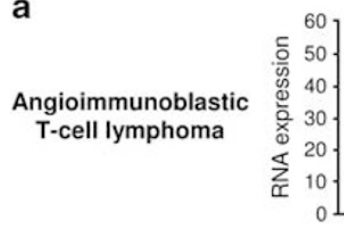

Microdissected CD $34^{+}$cells

b

Lymph node hyperplasia

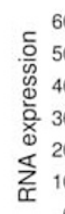

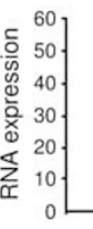

Mic

Microdissected $\mathrm{CD}^{+} 4^{+}$cells

C

Angioimmunoblastic T-cell lymphoma

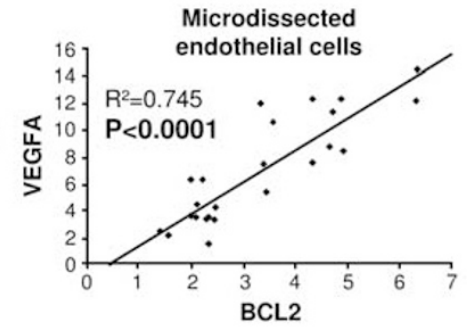

d

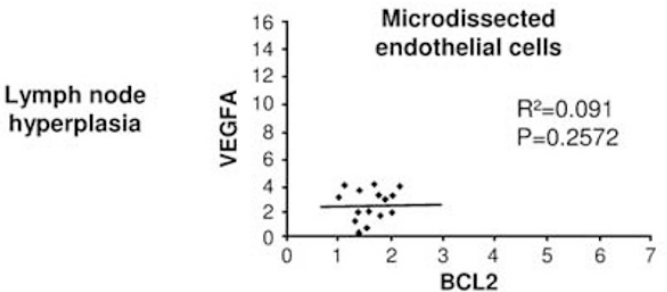

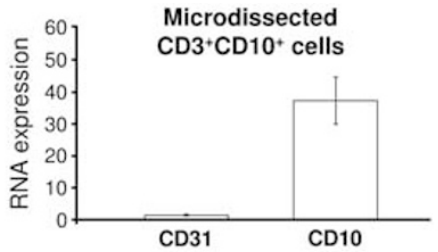
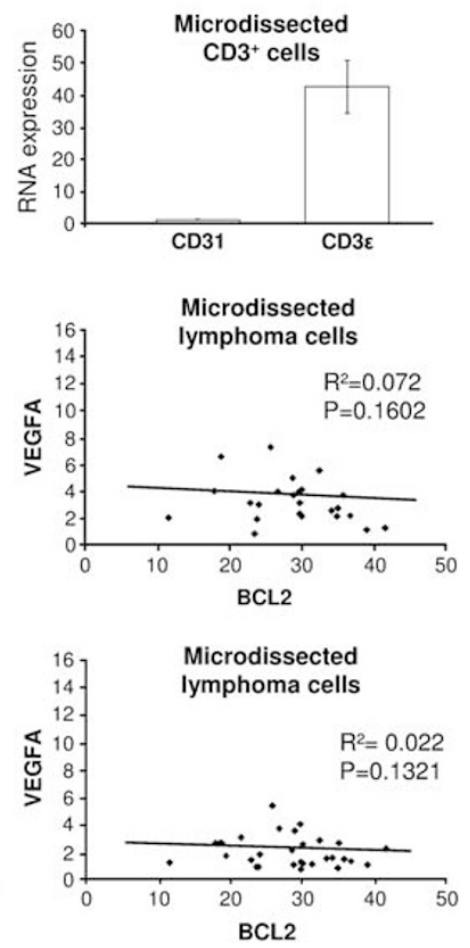

Figure 2 (a) Molecular evaluation of laser-microdissected CD34 ${ }^{+}$cells in angioimmunoblastic T-cell lymphoma: they express CD31 and not CD10, thus confirming the molecular profile of endothelial cells (left). Molecular evaluation of laser-microdissected CD3 ${ }^{+} \mathrm{CD} 10^{+}$ cells in angioimmunoblastic T-cell lymphoma: they express CD10 and not CD31, thus confirming the molecular profile of lymphoma cells (right). (b) Molecular evaluation of laser-microdissected CD34+ ${ }^{+}$cells in lymph node hyperplasia: they express CD31 and not CD10, thus confirming the molecular profile of endothelial cells (left). Molecular evaluation of laser-microdissected CD3 ${ }^{+}$cells in lymph node hyperplasia: they express CD3 $\varepsilon$ and not CD31, thus confirming the molecular profile of lymphocytes (right). (c) The expression of BCL2 mRNA in laser-microdissected CD34 ${ }^{+}$angioimmunoblastic T-cell lymphoma endothelial cells is significantly correlated with VEGFA mRNA expression levels in the same laser-microdissected cell population (left). BCL2 and VEGFA mRNA expression levels are not correlated in the same laser-microdissected cell population of $\mathrm{CD}^{+} \mathrm{CD}^{+} 0^{+}$lymphoma cells of angioimmunoblastic T-cell lymphoma (right). (d) In lymph node hyperplasia controls, no correlations are found between BCL2 and VEGFA mRNA expression levels whether for laser-microdissected CD34 ${ }^{+}$cells (left) or for laser-microdissected CD3 ${ }^{+}$lymphocytes (right).

$P=0.0017)$ (Figure 7), (ii) International Prognostic Index $(P<0.0001$ vs $P=0.0002)$, (iii) signs of tumor progression and extension (Bone marrow involvement $(P<0.0001$ vs $P=0.0004)$, Ann Arbor Stage $(P=0.0006$ vs $P=0.0018)$, elevated lactate dehydrogenase level $(P=0.0094$ vs $P=0.0397)$.

Within a median follow-up of 61 months, 17 patients (56\%) relapsed and 16 of them (53\%) died. The 2-year EFS and OS rate were, respectively, 41.3 and $72.9 \%$, with median EFS and OS at 18.5 and 39 months. Poor EFS and OS were correlated with high BCL2 levels, in microdissected CD34 ${ }^{+}$endothelial cells $(P=0.0129$ and 0.0231 , respectively) and in microdissected $\mathrm{CD} 34^{+} \mathrm{CD}_{105}{ }^{+}$neoangiogenic endothelial cells $(P=0.0092$ and 0.0104 , respectively) but not in microdissected CD3 ${ }^{+} \mathrm{CD} 10^{+}$lymphoma cells $(P=0.0612$ and 0.0783 , respectively).
Multivariate analyses revealed that BCL2 levels in microdissected $\mathrm{CD} 34^{+} \mathrm{CD} 105^{+}$neoangiogenic endothelial cells were independent adverse prognostic factors for event-free survival and overall survival $(P=0.0091$ and 0.0145 , respectively).

\section{Discussion}

We showed the coexpression of BCL2 and VEGFA in endothelial and lymphoma cells of angioimmunoblastic T-cell lymphoma, and the significant relation of BCL2 expression in neoangiogenic endothelial cells with microvessel density, International Prognostic Index, and signs of tumor progression.

BCL2 overexpression is a hallmark of follicular lymphoma cells. ${ }^{28}$ It has also been reported in 


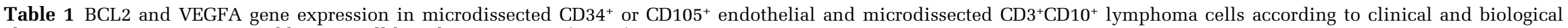
characteristics in angioimmunoblastic T-cell lymphoma patients $(n=30)$

\begin{tabular}{|c|c|c|c|c|c|c|c|c|c|c|c|c|c|}
\hline & \multirow[t]{3}{*}{ No. $(\%)$} & \multicolumn{4}{|c|}{ Microdissected CD $34^{+}$endothelial cells } & \multicolumn{4}{|c|}{ Microdissected $\mathrm{CD} 105^{+}$endothelial cells } & \multicolumn{4}{|c|}{ Microdissected $\mathrm{CD}^{+} \mathrm{CD} \mathrm{O}^{+}$lymphoma cells } \\
\hline & & \multicolumn{2}{|c|}{$B C L 2$} & \multicolumn{2}{|c|}{ VEGFA } & \multicolumn{2}{|c|}{$B C L 2$} & \multicolumn{2}{|c|}{$V E G F A$} & \multicolumn{2}{|l|}{ BCL2 } & \multicolumn{2}{|c|}{$V E G F A$} \\
\hline & & $X($ s.d.) & $\mathrm{P}$ & $X($ s.d.) & $\mathrm{P}$ & $X($ s.d.) & $\mathrm{P}$ & $X($ s.d.) & $\mathrm{P}$ & $X($ s.d.) & $\mathrm{P}$ & $X($ s.d.) & $\mathrm{P}$ \\
\hline \multicolumn{14}{|l|}{ Age (years) } \\
\hline$<60$ & $15(50)$ & $2.58(1.12)$ & 0.0679 & $5.71(3.77)$ & 0.7812 & $7.32(3.22)$ & 0.0598 & $13.27(3.84)$ & 0.6719 & $28.76(6.01)$ & 0.1526 & $2.27(1.35)$ & 0.1527 \\
\hline$>60$ & $15(50)$ & $3.76(1.68)$ & & $8.15(3.72)$ & & $9.91(2.68)$ & & $19.21(5.21)$ & & $26.56(7.82)$ & & $3.55(1.67)$ & \\
\hline \multicolumn{14}{|l|}{ Gender } \\
\hline Male & $14(47)$ & $2.49(1.82)$ & 0.0698 & $5.22(3.42)$ & 0.3126 & $6.83(2.81)$ & 0.0712 & 12.29 (4.39) & 0.4721 & $28.65(5.32)$ & 0.3256 & $2.45(1.19)$ & 0.0792 \\
\hline Female & $16(53)$ & $3.81(1.83)$ & & $8.54(3.55)$ & & $11.70(4.71)$ & & $16.27(5.01)$ & & $25.99(7.08)$ & & $3.59(1.52)$ & \\
\hline \multicolumn{14}{|l|}{ ECOG } \\
\hline $0-1$ & $12(40)$ & $2.29(1.21)$ & 0.0822 & $4.44(2.39)$ & 0.0725 & $7.21(3.22)$ & 0.0727 & $11.29(4.29)$ & 0.0532 & $28.31(7.82)$ & 0.9627 & $2.91(1.21)$ & 0.1628 \\
\hline $2-4$ & $18(60)$ & $3.97(1.51)$ & & $8.31(3.81)$ & & $10.17(3.71)$ & & $17.24(4.24)$ & & $29.02(6.93)$ & & $3.52(1.95)$ & \\
\hline \multicolumn{14}{|l|}{ Ann Arbor stage } \\
\hline II & $4(14)$ & $1.81(0.31)$ & & $2.79(1.29)$ & & $4.21(1.29)$ & & $11.22(3.61)$ & & $26.31(4.99)$ & & $1.49(0.60)$ & \\
\hline III & $7(23)$ & $2.12(0.41)$ & 0.0018 ** & $3.98(0.46)$ & $<\mathbf{0 . 0 0 0 1}^{* *}$ & $6.34(2.27)$ & $\mathbf{0 . 0 0 0 6}^{* *}$ & $14.87(4.01)$ & $<0.0001^{* *}$ & $27.67(2.12)$ & 0.8129 & $2.31(0.39)$ & $0.0085^{* *}$ \\
\hline IV & $19(63)$ & $4.09(1.28)$ & & $10.23(3.28)$ & & $11.71(3.27)$ & & $21.37(5.02)$ & & $27.81(6.37)$ & & $4.21(1.72)$ & \\
\hline \multicolumn{14}{|l|}{ B-symptoms } \\
\hline A & $8(27)$ & $2.17(1.10)$ & 0.0817 & $4.31(2.39)$ & 0.0815 & $7.42(3.01)$ & 0.0914 & $12.21(4.22)$ & 0.0673 & 26.79 (9.88) & 0.99854 & $2.21(1.02)$ & 0.0729 \\
\hline $\mathrm{B}$ & $22(73)$ & $3.64(1.52)$ & & $7.82(3.43)$ & & $9.42(4.12)$ & & $18.37(5.32)$ & & $27.12(6.39)$ & & $3.42(1.51)$ & \\
\hline \multicolumn{14}{|l|}{ Bone marrow involvement } \\
\hline Yes & $18(60)$ & $3.91(1.31)$ & $0.0004^{* *}$ & $9.11(3.02)$ & $<0.0001 * *$ & $12.29(3.28)$ & $0.0002^{* *}$ & $19.17(5.32)$ & $<0.0001^{* *}$ & $26.28(6.90)$ & 0.7103 & $4.01(1.44)$ & $<0.0001$ ** \\
\hline No & $12(40)$ & $2.12(0.89)$ & & $3.48(1.62)$ & & $6.21(1.97)$ & & $7.94(3.29)$ & & $22.90(6.11)$ & & $1.89(0.72)$ & \\
\hline \multicolumn{14}{|l|}{ Skin involvement } \\
\hline Yes & $9(30)$ & $3.88(1.39)$ & 0.1429 & $8.89(2.93)$ & $0.0292^{*}$ & $9.22(3.04)$ & 0.2134 & $18.31(4.29)$ & $0.0173^{*}$ & $25.21(4.12)$ & 0.6266 & $4.42(1.71)$ & $0.0221 *$ \\
\hline No & $21(70)$ & $2.98(1.41)$ & & $5.72(3.87)$ & & $7.42(2.21)$ & & $11.36(2.81)$ & & $27.32(7.11)$ & & $2.66(1.39)$ & \\
\hline \multicolumn{14}{|c|}{ International prognostic index } \\
\hline $\begin{array}{l}\text { Low risk- } \\
\text { intermediate low risk }\end{array}$ & $11(37)$ & $2.01(0.33)$ & 0.0002 ** & $3.06(0.75)$ & $<0.0001^{* *}$ & $4.17(1.32)$ & $<0.0001 * *$ & $8.21(3.26)$ & $<0.0001 * *$ & $28.83(5.17)$ & 0.2210 & $2.19(0.79)$ & $0.0105^{*}$ \\
\hline $\begin{array}{l}\text { Intermediate high } \\
\text { risk-high risk }\end{array}$ & $19(63)$ & $3.99(1.19)$ & & $10.05(3.54)$ & & $11.17(2.15)$ & & $21.37(5.17)$ & & $25.23(6.89)$ & & $3.89(1.56)$ & \\
\hline \multicolumn{14}{|l|}{ Lactate dehydrogenase } \\
\hline$<$ Normal & 7 (23) & $2.21(0.52)$ & $0.0397^{*}$ & 3.55 (1.69) & 0.1025 & $4.02(2.16)$ & 0.0094 * * & $10.21(4.72)$ & 0.7458 & $29.69(6.91)$ & 0.5927 & $2.37(0.90)$ & 0.0907 \\
\hline$>$ Normal & $23(77)$ & $3.62(1.47)$ & & $7.65(3.93)$ & & $10.22(3.32)$ & & $17.27(4.72)$ & & $27.27(6.21)$ & & $3.22(1.85)$ & \\
\hline
\end{tabular}

$P$-value obtained when comparing the subgroups of each characteristic.

${ }^{*} P<0.05$.

${ }^{* *} P<0.01$. 
lymphoma cells of few angioimmunoblastic T-cell lymphoma. ${ }^{29}$ However, BCL2 overexpression in endothelial cells has not been reported so far in angioimmunoblastic T-cell lymphoma.

The role of BCL2 in endothelial cells has been demonstrated by experimental studies. The specific blocking of BCL2 activity by anti-BCL2 antisense G3139, alters in vitro endothelial cell growth and tubular morphogenesis. ${ }^{12}$ In BCL2-deficient mice,

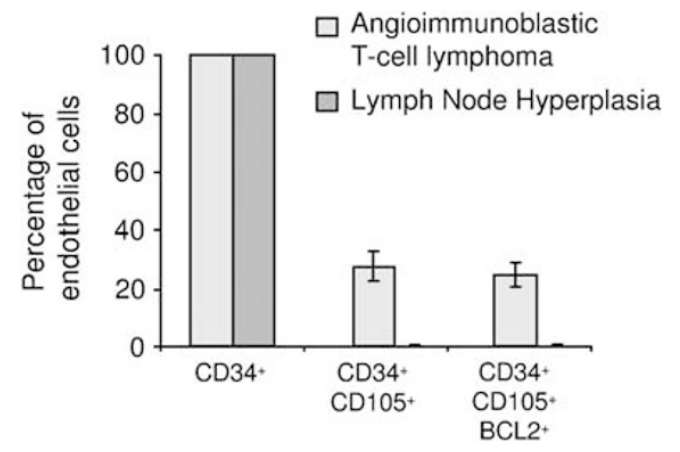

Figure 3 Proportion of endothelial cells expressing CD105 neoangiogenic marker and BCL2 in the 30 patients with angioimmunoblastic T-cell lymphoma and in the eight patients with lymph node hyperplasia. isolated retinal endothelial cells have reduced capacities of migration, tenascin-C expression, and adhesion to vitronectin and fibronectin. They also fail to form capillaries in Matrigel. ${ }^{30}$ On the contrary, experimental induction of BCL2 overexpression in HDMEC endothelial cells results in an enhanced angiogenic phenotype. ${ }^{31}$ BCL2-transduction in HUVEC endothelial cells induces the formation of chimeric vessels, and arteriogenic remodeling in immunodeficient mice. ${ }^{32}$ Moreover, the antiapoptotic activities of BCL2 correlate with vascular maturation and transcriptional modulation of HUVEC endothelial cells. ${ }^{33}$

BCL2 and VEGFA proteins were coexpressed in endothelial and lymphoma cells of the 30 angioimmunoblastic T-cell lymphoma cases we studied. However, a significant relation between BCL2 and VEGFA mRNA levels was only found in endothelial cells. Controls with laser-microdissected endothelial cells from lymph node hyperplasia showed that this correlation between BCL2 and VEGFA mRNA levels was specific for angioimmunoblastic T-cell lymphoma endothelial cells. Such a correlation for endothelial cells but not for tumor cells has also been identified in oral squamous cell carcinoma, ${ }^{8,34}$ where in vitro studies further demonstrated that BCL2

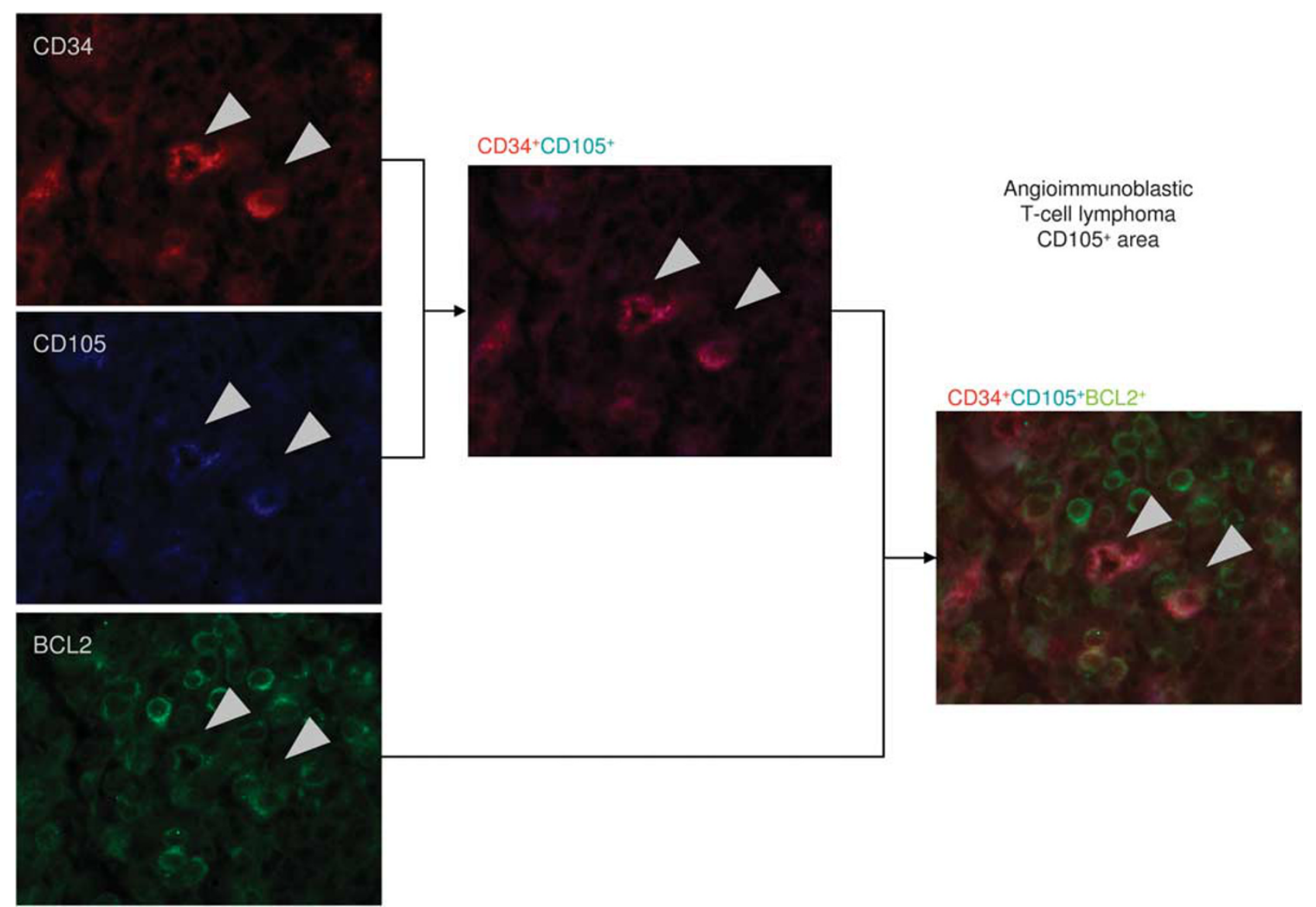

Figure 4 BCL2 expression in $\mathrm{CD}_{105}{ }^{+}$neoangiogenic endothelial cells of angioimmunoblastic T-cell lymphoma. In the CD34 ${ }^{+}$ angioimmunoblastic T-cell lymphoma endothelial population, BCL2 is coexpressed with CD105, a marker of neoangiogenic endothelial cells (triple immunofluorescent staining: CD34 in red, CD105 in blue and BCL2 in green). 


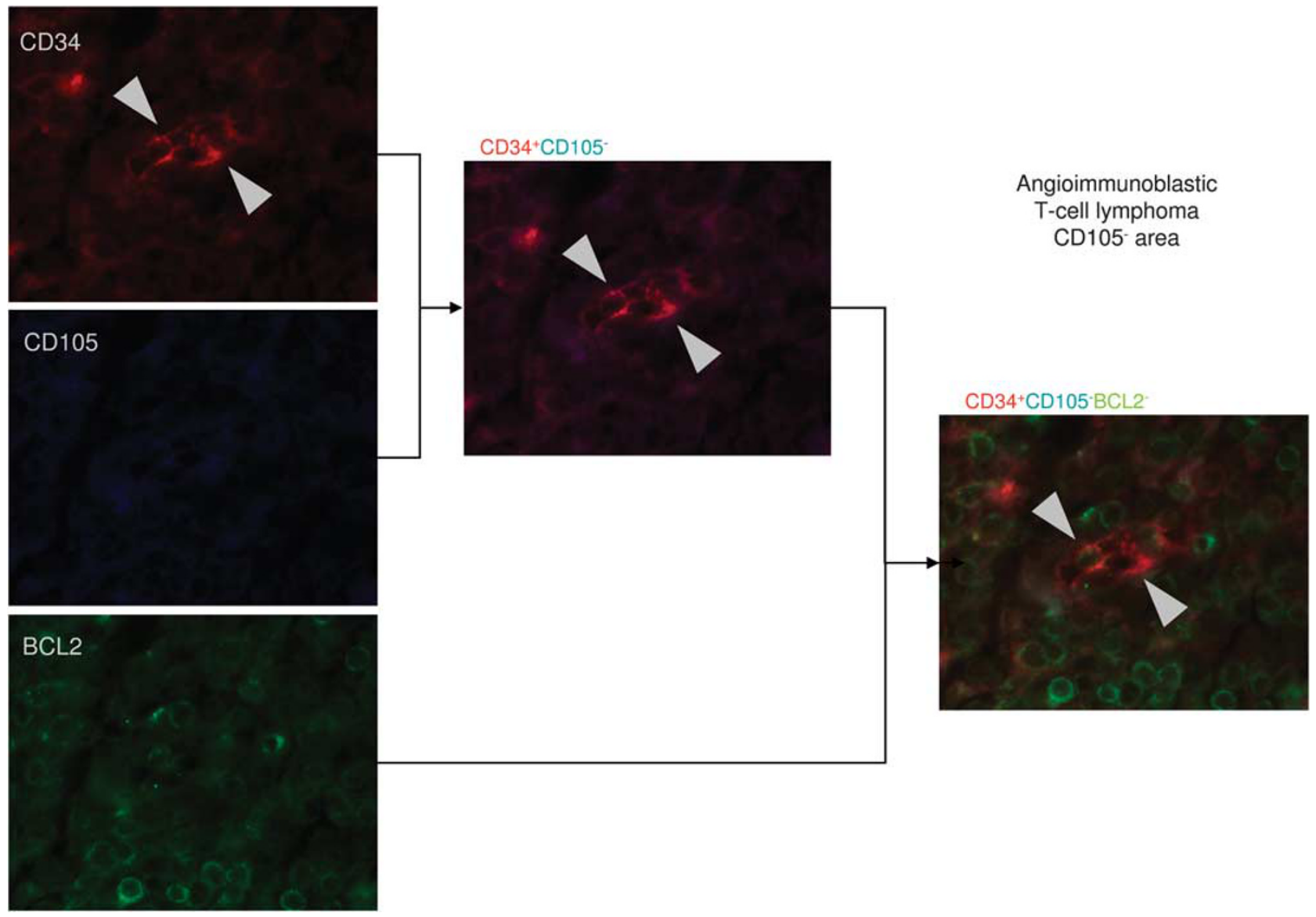

Figure 5 Absence of BCL2 expression in CD105- neoangiogenic endothelial cells of angioimmunoblastic T-cell lymphoma. No coexpression of BCL2 is found in angioimmunoblastic T-cell lymphoma areas where CD34 ${ }^{+}$endothelial cells do not express CD105 (triple immunofluorescent staining: CD34 in red, CD105 in blue and BCL2 in green).

a

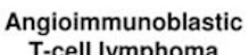
T-cell lymphoma
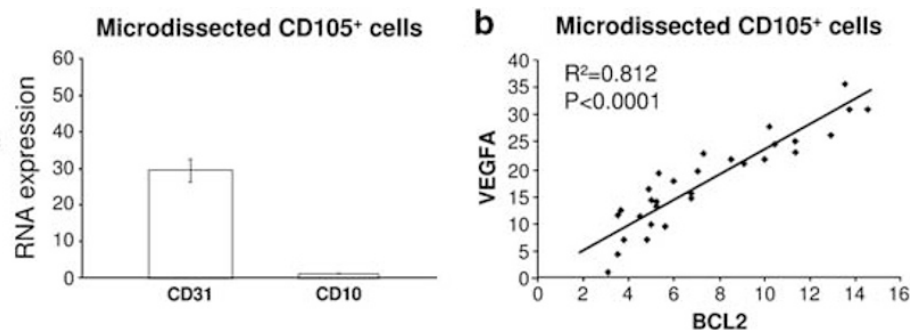

Figure 6 (a) Molecular evaluation of laser-microdissected CD105 ${ }^{+}$cells in angioimmunoblastic T-cell lymphoma: they express CD31 and not CD10, thus confirming the molecular profile of endothelial cells. (b) The expression of BCL2 mRNA in laser-microdissected CD105 ${ }^{+}$ endothelial cells of angioimmunoblastic T-cell lymphoma is significantly correlated with VEGFA mRNA expression levels in the same laser-microdissected cell population.

expression level in endothelial cells controls VEGFA expression in tumor cells. ${ }^{8}$ In xenografted squamous cell carcinoma cell lines, BCL2 crosstalk between endothelial and tumor cells through VEGFA leads to tumor growth and metastatic development. ${ }^{8,9,11,35}$

A neoangiogenic subtype of endothelial cells, expressing CD105, a TGF $\beta$-receptor type III auxiliary receptor, ${ }^{13}$ has been identified. ${ }^{36-38}$ CD105 expression on endothelial cells is related to tumor progression in squamous cell carcinoma, ${ }^{16}$ glioblastomas, ${ }^{15}$ and meningiomas. ${ }^{14}$ It correlates with survival in primary central nervous system lymphomas. ${ }^{17}$ In our study using immunostainings and laser-microdissection combined with molecular analyses, we demonstrate that in angioimmunoblastic T-cell lymphoma, only CD $34{ }^{+} \mathrm{CD} 105^{+}$neoangiogenic endothelial cells expressed BCL2.

The fact that BCL2 expression by these neoangiogenic endothelial cells is significantly related with microvessel density in the 30 angioimmunoblastic T-cell lymphoma cases we studied is coherent with the role of VEGFA production by endothelial cells in 

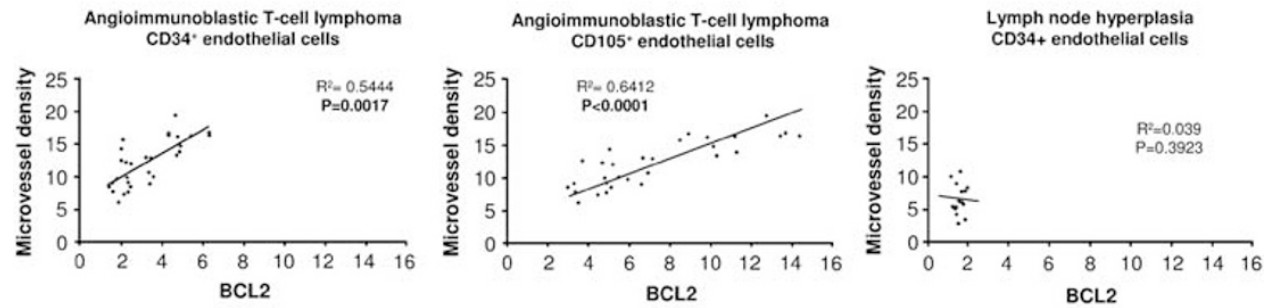

b

BCL2 in endothelial cells and proliferating index
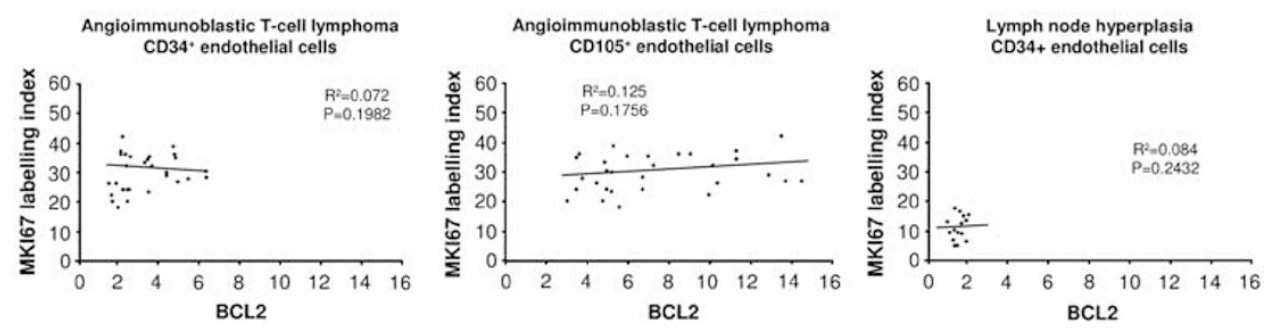

Figure 7 BCL2 in endothelial cells, microvascular density and proliferation index. (a) In microdissected CD34 ${ }^{+}$endothelial cells from angioimmunoblastic T-cell lymphoma lymph node, BCL2 mRNA expression level is significantly correlated with microvessel density (left). In $\mathrm{CD}_{105}{ }^{+}$neoangiogenic endothelial cells of angioimmunoblastic T-cell lymphoma, BCL2 mRNA expression is highly related with microvessel density. In contrast, BCL2 CD34 ${ }^{+}$endothelial mRNA level is not correlated with microvascular density in reactive lymph node hyperplasia. (b) In AITL, CD34 ${ }^{+}$endothelial as well as CD105 ${ }^{+}$neoangiogenic endothelial cell BCL2 mRNA levels are not correlated with KI67 proliferating index. In CD34 ${ }^{+}$endothelial cells of lymph node hyperplasia, no correlation was observed either.

tumoral angiogenesis. ${ }^{39}$ The further significant relations of BCL2 expression by neoangiogenic endothelial with International Prognostic Index and signs of tumor extension, as well as an independent prognostic factor also underline the role of angiogenesis in lymphoma progression, a fact recently identified by stromal gene signatures in large-B-cell lymphomas. ${ }^{40}$ Tumor development is characterized by a defective control of cellular homeostasis. The neoangiogenic endothelial BCL2 positives relations with International prognostic Index and signs of tumor extension, as well as an independent prognostic factor, and the absence of relation with the global Proliferation Index (i.e., stromal and tumoral cells) can be interpreted as an antiapoptotic action of neoangiogenic endothelial BCL2 on lymphoma cells.

\section{Acknowledgements}

We thank Mrs Angela Swaine Verdier who reviewed the English language of the manuscript. This study was funded by Institut National du Cancer, Cancéropôle Ile de France, Conseil Régional Ile de France, Agence Nationale de la Recherche, Programme Hospitalier de Recherche Clinique, and the Shanghai Commission of Science and Technology (08410708800; 09QH1401700).

Author contributions: Study design: PR and AJ; clinical data collection: JB, CT, and WLZ; assessment of experiment: CL and ILF; analysis of data: PR, WLZ, and AJ; manuscript writing: PR and AJ.

\section{Disclosure/conflict of interest}

The authors declare no conflict of interest.

\section{References}

1 Koster A, Raemaekers JM. Angiogenesis in malignant lymphoma. Curr Opin Oncol 2005;17:611-616.

2 Passalidou E, Stewart M, Trivella M, et al. Vascular patterns in reactive lymphoid tissue and in nonHodgkin’s lymphoma. Br J Cancer 2003;88:553-559.

3 Zhao WL, Mourah S, Mounier N, et al. Vascular endothelial growth factor-A is expressed both on lymphoma cells and endothelial cells in angioimmunoblastic T-cell lymphoma and related to lymphoma progression. Lab Invest 2004;84):1512-1519.

4 Aguiar Bujanda D. Complete response of relapsed angioimmunoblastic T-cell lymphoma following therapy with bevacizumab. Ann Oncol 2008;19:396-397.

5 Alizadeh AA, Advani RH. Evaluation and management of angioimmunoblastic T-cell lymphoma: a review of current approaches and future strategies. Clin Adv Hematol Oncol 2008;6:899-909.

6 Bruns I, Fox F, Reinecke P, et al. Complete remission in a patient with relapsed angioimmunoblastic T-cell lymphoma following treatment with bevacizumab. Leukemia 2005;19:1993-1995.

7 Dunleavy K, Wilson WH, Jaffe ES. Angioimmunoblastic $\mathrm{T}$ cell lymphoma: pathobiological insights 
and clinical implications. Curr Opin Hematol 2007; 14:348-353.

8 Kaneko T, Zhang Z, Mantellini MG, et al. BCL2 orchestrates a cross-talk between endothelial and tumor cells that promotes tumor growth. Cancer Res 2007;67:9685-9693.

9 Kumar P, Ning Y, Polverini PJ. Endothelial cells expressing BCL2 promotes tumor metastasis by enhancing tumor angiogenesis, blood vessel leakiness and tumor invasion. Lab Invest 2008;88:740-749.

10 Zhang CL, Song F, Zhang J, et al. Hypoxia-induced BCL2 expression in endothelial cells via p38 MAPK pathway. Biochem Biophys Res Commun 2010; 394:976-980.

11 Kumar P, Coltas IK, Kumar B, et al. BCL2 protects endothelial cells against gamma-radiation via a RafMEK-ERK-survivin signaling pathway that is independent of cytochrome c release. Cancer Res 2007; 67:1193-1202.

12 Stein CA, Wu S, Voskresenskiy AM, et al. G3139, an anti-BCL2 antisense oligomer that binds heparinbinding growth factors and collagen I, alters in vitro endothelial cell growth and tubular morphogenesis. Clin Cancer Res 2009;15:2797-2807.

13 Fonsatti E, Nicolay HJ, Altomonte $\mathrm{M}$, et al. Targeting cancer vasculature via endoglin/CD105: a novel antibody-based diagnostic and therapeutic strategy in solid tumours. Cardiovasc Res 2010;86:12-19.

14 Barresi V, Cerasoli S, Vitarelli E, et al. Density of microvessels positive for CD105 (endoglin) is related to prognosis in meningiomas. Acta Neuropathol 2007; 114:147-156.

15 Behrem S, Zarkovic K, Eskinja N, et al. Endoglin is a better marker than CD31 in evaluation of angiogenesis in glioblastoma. Croat Med J 2005;46:417-422.

16 Kyzas PA, Agnantis NJ, Stefanou D. Endoglin (CD105) as a prognostic factor in head and neck squamous cell carcinoma. Virchows Arch 2006;448:768-775.

17 Sugita Y, Takase Y, Mori D, et al. Endoglin (CD 105) is expressed on endothelial cells in the primary central nervous system lymphomas and correlates with survival. J Neurooncol 2007;82:249-256.

18 Swerdlow SH, Campo E, Harris NL, et al. WHO classification of tumours of hematopoietic and lymphoid tissues. 4th edn., IARC, 2008, pp 309-311.

19 Pautier P, Devidas A, Delmer A, et al. Angioimmunoblastic-like T-cell non Hodgkin's lymphoma: outcome after chemotherapy in 33 patients and review of the literature. Leuk Lymphoma 1999;32:545-552.

20 Weidner N, Semple JP, Welch WR, et al. Tumor angiogenesis and metastasis-correlation in invasive breast carcinoma. N Engl J Med 1991;324:1-8.

21 Vermeulen PB, Gasparini G, Fox SB, et al. Second international consensus on the methodology and criteria of evaluation of angiogenesis quantification in solid human tumours. Eur J Cancer 2002;38:1564-1579.

22 Vermeulen PB, Gasparini G, Fox SB, et al. Quantification of angiogenesis in solid human tumours: an international consensus on the methodology and criteria of evaluation. Eur J Cancer 1996;32A:2474-2484.

23 Konstantinou K, Yamamoto K, Ishibashi $\mathrm{F}$, et al. Angiogenic mediators of the angiopoietin system are highly expressed by CD10-positive lymphoma cells in angioimmunoblastic T-cell lymphoma. Br J Haematol 2009;144:696-704.
24 Laurent C, Fazilleau N, Brousset P. A novel subset of Thelper cells: follicular T-helper cells and their markers. Haematologica 2010;95:356-358.

25 Went P, Agostinelli C, Gallamini A, et al. Marker expression in peripheral T-cell lymphoma: a proposed clinical-pathologic prognostic score. J Clin Oncol 2006;24:2472-2479.

26 Soltani-Arabshahi $\mathrm{R}$, Leboeuf $\mathrm{C}$, Rivet $\mathrm{J}$, et al. Bcl-xL gene expression correlated with lower apoptotic cell numbers and shorter progression-free survival in PCFCL. J Invest Dermatol 2009;129: 1703-1709.

27 A predictive model for aggressive non-Hodgkin's lymphoma. The International Non-Hodgkin's Lymphoma Prognostic Factors Project. N Engl J Med 1993; 329:987-994.

28 Hoefnagel JJ, Vermeer MH, Jansen PM, et al. BCL2, Bcl-6 and CD10 expression in cutaneous B-cell lymphoma: further support for a follicle centre cell origin and differential diagnostic significance. $\mathrm{Br} J$ Dermatol 2003;149:1183-1191.

29 Jung JT, Kim DH, Kwak EK, et al. Clinical role of BCL2, Bax, or p53 overexpression in peripheral T-cell lymphomas. Ann Hematol 2006;85:575-581.

30 Kondo S, Tang Y, Scheef EA, et al. Attenuation of retinal endothelial cell migration and capillary morphogenesis in the absence of BCL2. Am J Physiol Cell Physiol 2008;294:C1521-C1530.

31 Karl E, Zhang Z, Dong Z, et al. Unidirectional crosstalk between Bcl-xL and BCL2 enhances the angiogenic phenotype of endothelial cells. Cell Death Differ 2007;14:1657-1666.

32 Enis DR, Shepherd BR, Wang Y, et al. Induction, differentiation, and remodeling of blood vessels after transplantation of BCL2-transduced endothelial cells. Proc Natl Acad Sci USA 2005;102:425-430.

33 Enis DR, Dunmore B, Johnson N, et al. Antiapoptotic activities of BCL2 correlate with vascular maturation and transcriptional modulation of human endothelial cells. Endothelium 2008;15:59-71.

34 Nor JE, Christensen J, Mooney DJ, et al. Vascular endothelial growth factor (VEGF)-mediated angiogenesis is associated with enhanced endothelial cell survival and induction of BCL2 expression. Am J Pathol 1999;154:375-384.

35 Nor JE, Christensen J, Liu J, et al. Up-Regulation of BCL2 in microvascular endothelial cells enhances intratumoral angiogenesis and accelerates tumor growth. Cancer Res 2001;61:2183-2188.

36 Kumar S, Ghellal A, Li C, et al. Breast carcinoma: vascular density determined using CD105 antibody correlates with tumor prognosis. Cancer Res 1999; 59:856-861.

37 Wikstrom P, Lissbrant IF, Stattin P, et al. Endoglin (CD105) is expressed on immature blood vessels and is a marker for survival in prostate cancer. Prostate 2002:51:268-275.

38 Duff SE, Li C, Garland JM, et al. CD105 is important for angiogenesis: evidence and potential applications. FASEB J 2003;17:984-992.

39 Carmeliet P. Angiogenesis in life, disease and medicine. Nature 2005;438:932-936.

40 Lenz G, Wright G, Dave SS, et al. Stromal gene signatures in large-B-cell lymphomas. N Engl J Med 2008;359:2313-2323. 